\title{
A Role Of Emotional Intelligence Improving Lecturer Performance
}

\author{
Budi Harni ${ }^{*}$ \\ ${ }^{*}$ Sekolah Tinggi Ilmu Ekonomi, Bogor, Indonesia \\ Corresponding Author:budi_harni@yahoo.com
}

\begin{abstract}
The objective of this study is to examine a role of emotional intelligence in improving lecturer performance. This study used a quantitative approach which surveyed 107 part-time of lecturers selected by a proportional random sampling of 3 (three) high school economics in Bogor. The result conveyed that there is positive and significant role of emotional intelligence in improving lecturer performance. It is shown that there is a positive significant between emotional intelligence with lecturer's performance with coefficient correlation $r_{y}=0,632$ and coefficient determination $r_{y}=0,400 \quad(40 \%)$ with the regression equation $\hat{Y}=27,86+0,8 X_{1}$, Another factor that effects the variable lecturer's of $60 \%$.
\end{abstract}

Keywords: emotional intelligence, lecturer's performance, high school economics.

\section{INTRODUCTION}

Lecturer performance is an important factor in the progress of a university. Lecturer performance is very important because the decline in performance of both individuals and groups in a university can have a significant impact on a university. So that in this case a leader has a fairly heavy task where he must always try to improve his performance and motivate his subordinates to be able to improve their performance to achieve college goals. The job of being a lecturer cannot be done by someone who does not have certain skills and qualifications as a lecturer. Lecturers are professions where as time progresses, he has more difficult roles and tasks and demands more innovative performance. The more innovative lecturers' performance is important for the success of educational implementation in order to improve the quality of education.

Universities have permanent lecturers and non-permanent lecturers who play an important role in transferring knowledge and transfer of attitude. They also become agents of change that are expected to be able to bring the educational organization in which they work to grow and develop and be able to build an intelligent society from the results of the education process held. Even though lecturers remain more prioritized in performance evaluation than nonpermanent lecturers. In reality, non-permanent lecturers have an important role in raising higher education in printing superior students, thus determining the quality of education and teaching in Higher Education is also located in non-permanent lecturers.

In reality the performance of lecturers is still low compared to the permanent lecturers in the teaching and learning process, research and community service because it is needed in the implementation of higher education in the College of Economics in the city of Bogor and even becomes one of the requirements to improve the effectiveness of the implementation of education in education high, therefore the performance of non-permanent lecturers is important as a component to improve the quality of education in higher education.

Lecturer performance is a significant factor in the process of achieving higher education goals, so that if the performance of the lecturer is good then the progress of the College of Economics will be achieved, and vice versa. As a lecturer in higher education, a lecturer is required to strive to manage all activities in providing classroom instruction as effectively as possible and as efficiently as possible so that the educational process is as expected.

Emotional intelligence is to monitor and control one's own feelings and those of others and to use these feelings to guide thoughts and actions, so that emotional intelligence is needed for success in work and produces outstanding performance in work. In addition, emotional intelligence, an attitude a person has in managing emotions, self-motivating, empathy by showing sincerity in doing work by using emotions and fostering relationships with other people so as to improve the performance of lecturers in the learning process in universities by producing quality student outcomes. This is possible because the dimensions contained in emotional intelligence can lead someone to understand their position appropriately in the midst of organizational dynamics, including self-motivation, 
empathy and fostering relationships with members of the organization in the interests of the organization.

Performance theory according to Schermerhorn et.al (2010), to determine organizational and external performance can be seen from 5 (five) influencing factors, namely: a) knowledge, b) skills, c) ability, d) attitude and e) behavior . Colquit et al (2009: 37 ), suggests that performance is the value of a set of employee behaviors that contribute positively or negatively to achieving organizational goals. Basically Performance has three dimensions, namely (a) task behavior, (b) moral behavior, and (c) challenging behavior.

Based on several opinions and understanding of the theory outlined, it can be synthesized that the performance of lecturers is the work of lecturers who contribute, both in quantity and quality, to the achievement of organizational goals, with measurement indicators: 1) Making learning plans, 2) teaching and learning outcomes 3 ) learning outcomes 4) evaluation the same, 5) report making

Moshe Zeidner et al (2009) suggests that theories of emotional intelligence (emotional intelligence) are divided into three ways about understanding emotional intelligence, as follows:

a. Ability models, emotional intelligence as abilities, where individuals who have high emotional intelligence, are superior to individuals who have low emotional intelligence in carrying out certain activities related to emotions.

b. Mixed models, a broader conception and emotional intelligence include abilities and qualities such as personality traits and motivation that can help individuals use emotional intelligence in real life.

c. Emotional intelligence as a trait (trait emotional intelligence), is a comprehensive personality factor that represents self emotions, so that individuals have personalities that are directly related to emotional functions, such as: self-confidence, assertiveness, and empathy. This researched which focus to trait.

Stephen R. Covey (2005) reveals that emotional intelligence is, self-awareness, social sensitivity, empathy, and efforts to communicate well with others. Emotional intelligence is sensitivity about the right time, social propriety, and courage to acknowledge weaknesses, express and respect differences.

Stephen R. Covey explained that there are five main components of emotional intelligence that are commonly accepted are: a) Self-awareness, b) Personal motivation, c) Self-regulation, d) Empathy is understanding the way other people see and feel various things, e) Socialization and communication, which is related to how to overcome differences, solve problems, produce creative solutions and interact optimally to pursue common goals.

Furthermore Stephen R. Covey argued that the best and systematic way to develop these five dimensions of EQ is through seven highly effective human habits, namely: be proactive, start with the ultimate goal, prioritize the main, think win-win, try to understand first, then try to understand, create synergy, and sharpen the saw.

From the above theoretical studies and definitions, it can be synthesized that emotional intelligence of individual personality characteristics is comprehensive in regulating emotions, understanding one's emotions and controlling emotions to think and behave rationally, with indicators as follows: identifying emotions, managing emotions, recognizing the emotions of others, motivating yourself, managing the emotions of yourself and others.

\section{RESEARCH METHODS}

This study uses quantitative data analysis with survey methods. The use of this method aims to obtain a concrete and measurable preliminary picture for conducting research. Known results in the field based on statistical data analysis, are used as the main basis for qualitative research. The population in this study were non-permanent lecturers at the College of Economics in the city of Bogor with a random sample of 107 people from a population of 146 people. The quantitative research phase starts with:

1. Test analysis requirements

a) Test the estimated normal error error using the liliefers formula,

b) Test the variance homogenity using the Barlett test

2) Hypothesis Test: a) Regression Linearity Test, b). Correlation Test

\section{RESULTS AND DISCUSSION}

Hypothesis testing results show that there is a functional relationship between $\mathrm{X}$ and $\mathrm{Y}$ presented in the form of a simple regression equation as follows: $Y$ $=27.86+0.8 \mathrm{X}$, with a correlation coefficient ry $=$ 0.632 The coefficient of determination $\mathrm{r} y=0.400$, which is very significant $(0.05)$ after being tested by the $\mathrm{F}$ test. This means that $40 \%$ of the variation in lecturer performance data can be explained by Emotional intelligence, while $60 \%$ is contributed by other variables that have a relationship with the improvement of Lecturer Performance. The results of previous studies that support by Paiman, the relationship between Emotional Intelligence and Teaching Creativity with Teacher Performance ", there is a positive relationship between Emotional intelligence and teacher performance with regression $Y$ $=27,86+0,8 \times 1$ and correlation coefficient ry1 $=$ 0,632, this means more high Emotional Intelligence score, the higher the score of lecturer performance. Thus the results of this study further support the results of previous studies regarding the existence of a positive relationship with lecturer performance. Similarly, based on qualitative analysis through observation, 
interviews, document review FGD, it can be seen that there is a relationship between Emotional Intelligence and Lecturer Performance. This is reinforced by the results of quantitative research, each increase in independent variables will improve the performance of lecturers by: a) Appreciating Placement (The Value Placed on People), b) Available Openness of Available Options, c) Loyalty and congeniality (Friedliness and Congeniality).

This is consistent with the theory of Emotional Intelligence by Moshe Zeidner, Gerald Mathews and Richard Robert that Emotional Intelligence as Trait (Trait Emotional Intelligence), is a comprehensive personality factor that represents the emotions of the self, so that an individual has a personality related to emotional functions such as: confidence, assertiveness and empathy. Thus a lecturer who has a high organizational culture andeEmotional intelligence together will be able to improve the performance of lecturers.

The findings in this study indicate that if the lecturer performs his duties and functions is able to create, familiarize and develop personality well and apply organizational culture within himself and in his organization well and is able to organize the emotional lecturers well and proportionally and jointly have a strong desire, the power of movement and enthusiasm in carrying out the task by controlling his emotions and the lecturer who showed his work performance and chose to remain with his institution for the long term, of the three things, it will be able to improve the Performance of Lecturers. This is in line with the theory put forward by Gibson at.al, Stepehen Robbins (Big Five Model) and Jerald Greenberg and Robert A. Baron defines organizational culture as a cognitive framework consisting of attitudes, values, behavioral norms, and shared expectations of members of the organization.

While the theory of Emotional Intelligence by Moshe Zeidner, Gerald Mathews and Richard Robert that Emotional Intelligence as trait (Trait Emotional Intellilgence), is an overall personality factor that represents the emotions of the self, so that an individual has a personality associated with Emotional functions such as: confidence, assertiveness and empathy.

The pattern of relationships that can be seen from the results of this study is the correlation between Emotional Intelligence and Lecturer Performance that is ry $=0.632$ has a tendency that is almost the same, however, each independent variable the same can contribute to improving Lecturer Performance.

Findings of other factors that allegedly contributed to the achievement of lecturer performance were based on the results of observations, interviews and documentation of qualitative research in the field including: 1). Leadership of the Chairperson of STIE, 2) Motivation of lecturer work, 3) Personality.

\section{CONCLUSION}

There is a very significant positive relation ship between Emotional Intelligence and Lecturer Performance, meaning that the higher the Emotional Intelligence, the higher the Lecturer Performance. Other variables that have a relationship with the improvement of lecturer performance are: lecturer work motivation, work environment, lecturer discipline, Emotional intelligence, job satisfaction, commitment of lecturer work and organizational climate. Increased Emotional Intelligence can be done by observing:

a. In the average indicator, 1), identifying emotions, 2) motivating oneself, c) managing emotions, need to be maintained and so that lecturers and members of the organization respect each other more to be polite and help each other. Besides giving each other motivation they always work continuously.

b. While the low mean value is an indicator: 1) managing emotions, 2) recognizing the emotions of others needs to be improved. High schools encourage lecturers and organizational citizens to be more polite when experiencing various difficulties at the same time and encourage lecturers to be more trying to calm down. In addition, high schools and organizational citizens encourage lecturers not to discriminate between the emotional expressions of lecturers depending on who they are facing. Thus high schools, organizational citizens and lecturers always maintain mutually unwanted behavior and conditions to maintain stability.

\section{REFERENCES}

Aref Mchry Ramy, Ali Akbar Amin Beydokhty and Lale Jamshidy. 2014. Correlation between Emotional Intelligence and Creativity Factors. International Research Journal of Management Sciences. Vol.2

Ary Ginanjar Agustian, 2005, ESQ, Emotional Spritual Quotient, Jakarta : Arga

Badeni, Kepemimpinan dan Perilaku Organisasi ,Bandung : Alvabeta, 2013

Goleman, Daniel, 2009. Emotional Intellegence, Kecerdasan Emosional Mengapa Kecerdasan Emosional lebih penting dari $\mathrm{IQ}^{\wedge}$ terjemahan $\mathrm{T}$. Hermaya Jakarta: Grammedia Pustaka Utama,

Hellriegel, Don and Sloeum, John W.,2011. Organizational Behaviour, $13^{\text {th }}$ edition, SouthWestern : ChangeLearning 
Ivancevich, Konopaske and Matteson, 2012. Organizational Behavior and Management, eighth edition ,New York :McGraw-Hill

Jerald Greenberg \& Robert A. Baron, 2008. Behaviour in organizations, New Jersey : Pearson International, Inc.

Kinicki, Angelo \& Williams, Brian K. 2008, Management : A Practical Introduction, New York : MacGraw-Hills Companies, Inc.,

Kreitner and Kinicki, 2008. Organizational Behaviour, New York : McGraw Hill Companies, Inc.

Maria Jose Sanchez Riz, Juan Carlos Perez Gonzales, and K.V. Petrides. The relationship trait emotional intelligence and creativity across subject domains, Springer Science Business Media, Vol.35, No.1, June 2011

Mohammad Shahhosseini, Abu Daud Silong "Relation between Transactional Transformational Leadership Styles, Emotional Intelligence and Job Performance" Departmen of Professional and Continuing Education .University Putra Malaysia. Education University. International Refereed Research Journal, Vol.1-IV,Issue-I(1), January 2013 (15).www.researchersworld.com

Moshe,Gerald Matthews, and Richard D.Roberts.2009. What We know about Emotional Intelligence,Cambridge,MA : Massachusetts Institute of Technology.

Schermerhorn, J.R.,Jr., Hunt J.G., Osborn,R.N., UhlBien, M.. 2011, Organizational Behaviour. ,John Wiley \& Sons Asia 